\title{
Managing Supply Chain Disturbances - Review and Synthesis of Existing Contributions
}

\author{
Michael Schenk and Volker Stich \\ Institute for lndustrial Management at RWTH Aachen University \\ (FIR an der RWTH Aachen), Germany \\ \{michael.schenk, volker.stich\}@fir.rwth-aachen.de
}

\begin{abstract}
Companies suffer the effects of disturbances in supply chains more than ever. Highly dynamical consumer demands and globalized supply chains often lead to unplanned supply chain events through to break-downs causing inability to supply. Consequently, concepts for an efficient supply chain disturbance management are needed, preferably with a real-time reaction to disturbance events. Academic literature comprises many investigations dealing with such approaches. In this paper we examine both a range of methodological contributions to design resilient supply chains and approaches for the flexible coordination of supply chain processes in case of disturbances. After summarizing the major contributions, we point out an approach for a real-time supply chain disturbance management with the target to achieve the required flexibility for coping with supply chain disturbances.
\end{abstract}

Keywords: Supply Chain Management, Supply Chain Disturbances, Supply Chain Resilience, Supply Chain Event Management, Disturbance Management.

\section{$1 \quad$ Introduction}

The rising global cross-linking of production and sales regions increases steadily the complexity of supply chains. This leads to an increasing sensitivity to disturbances while in the meantime the requirements of the availability, the time of delivery and the security of supplies within the supply chain increases. [1, 2, 3]

The complexity of this development affects not only strategic considerations of industrial companies, but is also a constant component of their daily business. The companies have to meet high requirements on all levels, from the supply chain design topdown to the supply chain execution. Especially the security of the infrastructure needs to be ensured and complex supply chain processes need to be feasible, despite the high specialisation within the supply chain partners, the low stock and time buffers and the information shortcoming between supply chain partners. The industrial companies currently show obvious deficiencies in managing disturbances within their supply chains. On the one hand the understanding of disturbances and their impacts on the supply chain as well as a suitable integration of a cross-company disturbance management are not developed. On the other hand the applied ICT systems cannot stand up to the increasing requirements, because their implemented set of actions isn't applicable in most cases to counteract occurring disturbances with the required excellence [4]. 
In recent years the research has therefore generated different approaches to deal with the increasing impacts of supply chain disturbances [5, 6, 7]. Also, first ICT based approaches like the supply chain event management are developed to reduce the vulnerability of supply chains by providing real-time information of disturbances.

In the next chapter, we will give an outline both of recent literature on the design of resilient supply chains and operative management approaches for dealing with disturbances in supply chains. In chapter three we will point out the deficits of the existing approaches and finally identify further need for research, including a first example.

\section{Literature Review on Supply Chain Disturbances Management}

\subsection{Designing Resilient Supply Chains}

The design of resilient supply chains is one prominent potential to compete with the growing market dynamics and the increasing vulnerability of global supply chains. But due to the recentness of this topic hardly any literature can be found that deals with this subject. According to [4] and [8] resilient supply chains possess the ability to compete with unpredicted disturbances and quickly regain their original state or move over to a new, improved state and to adapt to the new constraints. Therefore, [9] defined four fundamental principles. First of all, the business processes need to be reengineered by taking into account both possible disturbances and the aim to reduce complexity. Further principles are the need for intense cooperation within the supply chain, high supply chain agility as well as the setup of a supply chain risk management culture.

[10] identified based on a literature review different management strategies to mitigate the impact of disturbances with all can be assigned to the above mentioned principles. [11] highlighted in his work that from all assigned strategies, two strategies have the highest potential to achieve resilience. It's the raise of flexibility and the integration of redundancies by provision of additional capacities.

Following the strategy of flexibility [12] described in their approach a design method for a reconfigurable supply chain network by optimizing inventory allocation and transportation routing. [13] also designed a model of a multi-stage global supply chain network including rating a set of risk factors. The model shows, that by an interechelon shifting of quantity flows, the overall cost of the supply chain can be minimized in the event of disturbances.

Even though all authors refer in their way to the four principles of [9], some authors indicate that not all of the included strategies are generally adaptive as they have their specific downsides. The strategy of redundant capacities for example is accompanied by high cost and acts opposed to the lean thinking which many companies are following [11]. On the other hand, the strategy to increase flexibility with the effect to react faster to disturbances comes along with significant lower downsides. 
[14] developed a method for the evaluation and selection of the preferred strategy to increase the supply chain resilience as preceding to the implementation of any action a cost-benefit analysis is inevitable. [15] also developed a method for evaluation based on a control engineering approach. Counter-intuitively their findings imply that optimum solutions for resilience do not create a system that is robust to disturbances affecting the lead time.

However, many fundamental elements of supply chain resilience, e.g. the links between risks and implications for supply chain management as well as their interconnection, are still unknown and there is still a lot of research that has to be done to close these knowledge gaps.

\subsection{Increasing the Flexibility of Supply Chain Planning and Control Processes}

As seen in the preceding chapter, based on the design of resilient supply chains, companies need to seek for new management methods to cope with disturbances on the planning and execution levels in existing supply chains with the target to increase their flexibility.

The mayor part of research works on this topic, especially the older ones, is focusing on design models to support the flexibility management in a specific production unit or a particular company and is missing the aspects of cross-company processes between the supply chain partners. [16] gives a comprehensive overview on such approaches.

In the research project PROLOG ([17]) concepts for prospective disturbances in supply chains were developed resulting in a guideline for the implementation of a preventive disturbance management by an early identification of internal and external disturbances. The approach is limited to guidelines for the project management of a individually performed disturbance management.

On the other hand [18] analyzed symptom patterns for disturbances in company networks and allocated adequate action propositions. The work, however, concentrates on the strategic to tactical level of the supply chain planning and control and describes many interdependencies only qualitatively. A coordination concept in the form of processes and information flows for the reaction on disturbances is also not subject of the work. Still, both approaches either don't or only marginally examine enterprise-wide interdependencies in supply chain planning associated to the disturbance management. Therefore the following research approaches explicitly aim to improve the coordination of supply chain planning and control tasks.

[19] developed an agent-based concept for cross-system production planning to increase the responsiveness in the supply chain. The focus of the work is the examination of the information exchange and the design of the various planning agents. However, interdependencies of logistical disturbances are not considered in detail.

The aim of the research project IPRONET [20] was the development of an internet based tool for the cross company support of manufacturing companies in supply chains. However, the disturbance management is reduced to the early identification of capacity constraints by an increased demand or reduced facilities and the simulative calculation of action possibilities. 
In the research alliance LINET, the aim of a cooperative requirement and capacity planning was pursued for the supply chains in the automotive industry [21]. Its core functionalities include the monitoring of bottleneck capacity, coordination of production programs, the simulation of capacity allocation plans as well as a workflow supported emergency management. The approach from [22] focused on a collaborative supply chain re-scheduling. It allows cooperative re-scheduling by the selection of the type of transport for sending components from one supply chain partner to another based on the target date and the costs to assemble the final product. Further, [23] designed in his work a case-based reasoning model for the selection of adequate actions to effectively deal with supply chain disturbances.

Another mayor topic to increase the flexibility of supply chain and thus be able to react faster is the enhancement of transparency of information in supply chains [24, 25, 26, 27]. Existing Supply chain event management systems (SCEM systems) are therefore a good leverage point. Based on a target-performance comparison they detect disturbance events and support the monitoring, planning and control of supply chains [27]. Another model for evaluation and control of risks in supply chains regarding both cost and environmental (e.g. traffic, weather) influences can be developed by using available approaches e.g. the complex event processing. Therefore flows of events from the supply chain are aggregated and combined to monitor parameters in real-time [28, 29].

Regarding existing supply chain software [26] underlined the innovation of supply chain event management systems in the functionalities of monitoring and notification as well as in the optimization of supply chain processes using long-term data evaluations. But in general nowadays available SCEM systems are still limited to monitor unplanned events and inform affected business units. To take measures like the replanning of supply chains processes conventional systems as ERP or APS systems are commonly used. SCEM systems still apply as mere pulsing devices which do not give any active decision support [30]. They still lack both in the identification $\&$ management and the communication \& coordination of disturbances. The limited consideration of logistical interdependences and the insufficient differentiation of disturbances lead to a deficient possibility to derive action propositions and lower the consistency from the identification of disturbances to the adjustment.

[31] stated in his work the importance of incentives and trust among multiple supply chain partners. If supply chain partners lack of trust to each other, then even a basic integration and real-time data flows will be problematic. Also, the whole supply chain will suffer if partners have no incentives to orchestrate their technology with the others.

\section{Creating a Real-Time Supply Chain Disturbance Management}

The literature review gives an overview, how today's methods and solutions from the supply chain management encounter the challenges of an increasing vulnerability to supply chain disturbances. As the review on the design approaches for resilient supply 
chains has shown, one mayor potential lies in the strategy of more flexible supply chains including a faster reaction to disturbances and an intense cooperation between the supply chain partners. But as seen, the existing approaches for the operational disturbance management on the supply chain level are still insufficiently designed. In this area, on the one hand the disturbance management is not considered entirely with all its facets, and on the other hand the shown approaches do not focus the real-time reaction to disturbance events and their impacts on the supply chain. This problem is extended by the lack of a comprehensive ICT-based support by supply chain event management systems.

Table 1. Overview of major contributions to the management of supply chain disturbances

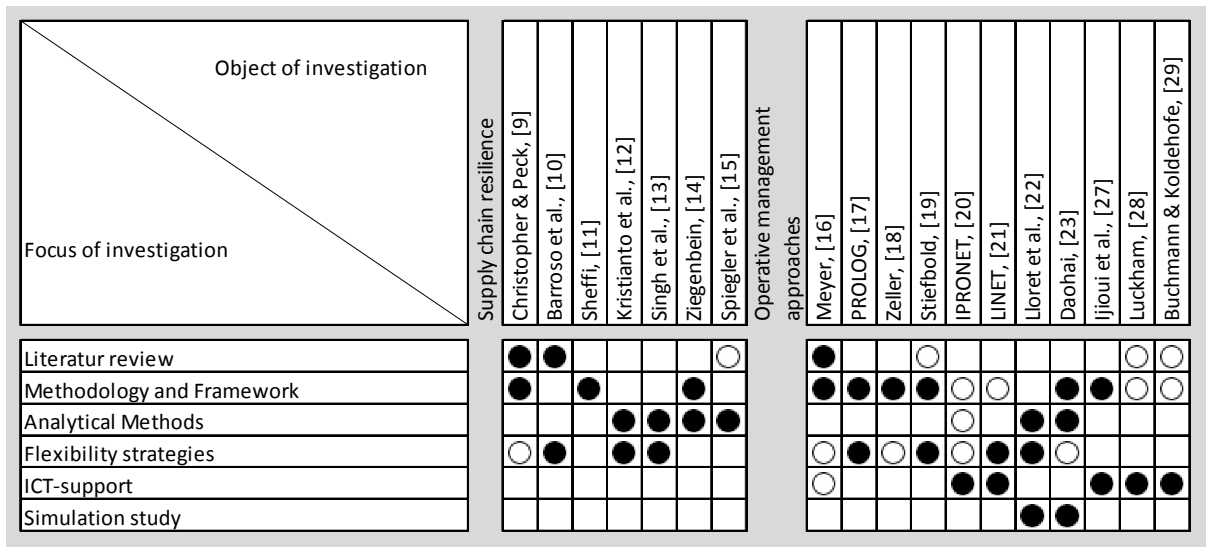

Based on the preceding literature review on existing approaches and the summarization of arisen potentials, different requirements can be derived to achieve the target of a real-time supply chain disturbance management. Besides the basic requirements for a holistic consideration of the supply chain disturbance management, including the cross-company coordination between supply chain partners and an increased transparency by the availability of real-time information on disturbances in the supply chain, also aspects of a sociotechnical integration of human and technics, the recursive design of the system and the sufficient interconnection between the different planning and execution levels need to be ensured. As an example how to lever these potentials, the authors want to highlight the on-going research project SMART LOGISTIC GRIDS. The focus of the research project is the design of an ICT-based system to provide adequate action propositions to encounter disturbance events and consequently increase the efficiency and robustness of the supply chain. This requires a flawless integration of different actors along the supply chain, as well as an increased information transparency and availability of disturbance events. Focal issues are the development of a supply chain monitoring and control unit and the provision of global supply chain events by a cloud service. The information about supply chain events is provided by the cloud service, which gathers and aggregates it to complex events. In the supply chain control unit this information is compiled and visualized. The unit enables an 
optimized execution and control of the supply chain based on the aggregated real-time information of the supply chain. The system provides different, evaluated action propositions to optimize the supply chain both by economical and resource efficiency considerations. Thus additional transport costs due to problems in the supply chain can be reduced or entirely avoided and an increased deliver capacity of the supply chain can be ensured.

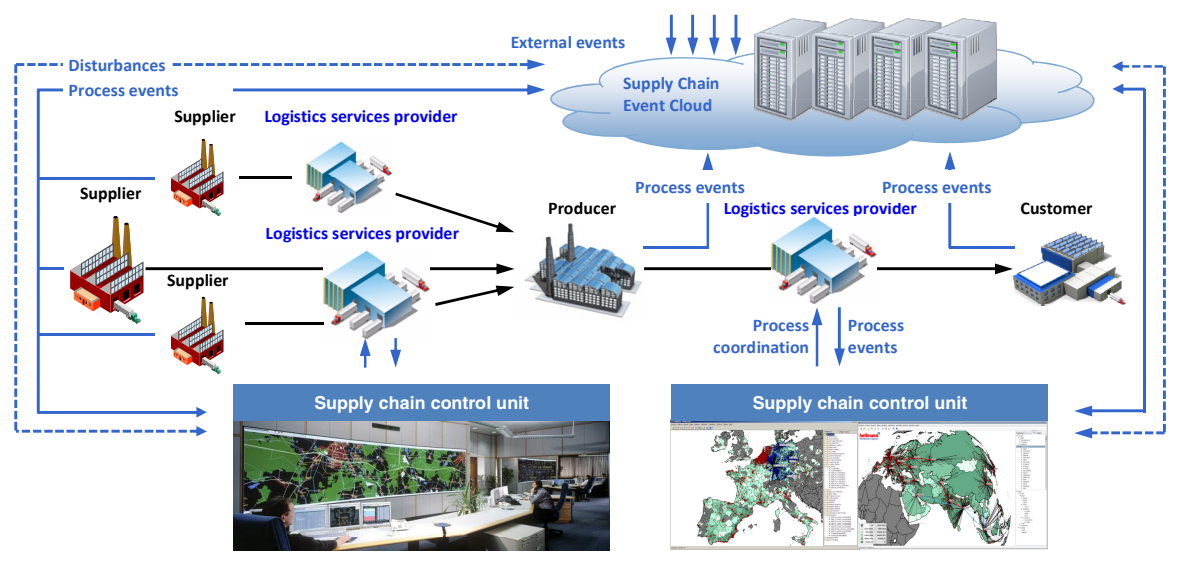

Fig. 1. Target system of the research project Smart Logistic Grids

\section{Conclusion}

The increasing dynamics in consumer demand patterns and the vulnerability of globalized supply chains leads to an increased requirements for coping with supply chain disturbances. As the literature review shows, different works already approach the topic of designing resilient supply chains and managing disturbances in a supply chain. Further, existing ICT solutions like supply chain event management systems partly support to handle supply chain disturbances. But despite the amount of ongoing research and the flurry of supply chain improvement programs, the competitive advantage and distinguish characteristic of future supply chains will be their flexibility, in particular to react on supply chain disturbances in real-time. Therefore, real-time information, real-time coordination between supply chain partners, and optimized action propositions are needed. The presented research project Smart Logistic Grids focuses such an approach by developing an event cloud and a supply chain control unit. Furthermore, a closer collaboration between industry and research units is need, to develop, implement and evaluate effective actions to supply chain disturbances. Thus, best practices can be gathered and standards be developed.

Acknowledgement. This paper as well as the project SMART LOGISTIC GRIDS are funded by the Federal Ministry for Economic Affairs and Energy (BMWi; funding code: 19 G 13002C). 


\section{References}

1. Deloitte: Supply Chain Resilience: A Risk Intelligent approach to managing global supply chains, p. 7 (2012)

2. The Business Continuity Institute: Supply Chain Resilience 2011 - An international survey of more than 550 organizations from over 60 countries, which considers the causes and consequences of disruption, the techniques and approaches to identify key supply chains, and methods to gain assurance of resilience capability. The Business Continuity Institute (2011)

3. Henke, M., Lasch, R., Eckstein, D., Neumüller, C., Blome, C.: Supply Chain Agility. Strategische Anpassungsfähigkeit im Supply Chain Management. Bundesvereinigung Logistik (BVL) e.V., Bundesverband Materialwirtschaft, Einkauf und Logistik e.V. (BME), Bremen 10 (2012)

4. Rice, J.B., Caniato, F.: Building a Secure and Resilient Supply Network. Supply Chain Management Review 7(5), 22-30 (2003)

5. Craighaid, C.W., Blackhurst, J., Rungtusanathan, M.J., Handfield, R.B.: The Severity of Supply Chain Disruptions: Design Characteristics and Mitigation Capabilities. Decision Sciences 38(1), 131-156 (2007)

6. Kiryazov, K.: Netzwerkorientiertes Supply Chain Controlling und Risikomanagement. Diplomica Verlag, Hamburg (2011)

7. Manuj, I., Mentzer, J.T.: Global supply chain risk management strategies. International Journal of Physical Distribution\& Logistics Management 383, 192-223 (2008)

8. Sheffi, Y., Rice, J.B.: Building the Resilient Enterprise. MIT Sloan Management Review 47(1), 41-48 (2005)

9. Christopher, M., Peck, H.: Building the Resilient Supply Chain. International Journal of Logistics Management 2(15), 1-13 (2004)

10. Barroso, A.P., Machado, V.H., Barros, A.R., Machado, V.C.: Toward a Resilient Supply Chain with Supply Disturbances. In: 2010 IEEE International Conference on Industrial Engineering and Engineering Management (IEEM), pp. 245-249. IEEE Press, New York (2010)

11. Sheffi, T.: Building a resilient Supply Chain. Harvard Business Review 1(8), 1-12 (2005)

12. Kristianto, Y., Gunasekaran, A., Helo, P., Hao, Y.: A model of resilient supply chain network design: A two-stageprogramming with fuzzy shortest path. Expert Systems with Applications 41, 39-49 (2014)

13. Singh, A.R., Mishra, P.K., Jain, R., Khurana, M.K.: Design of global supply chain network with operational risks. Int. J. Adv. Manuf. Technol. 60, 273-290 (2012)

14. Ziegenbein, A.: Supply Chain Risiken: Identifikation, Bewertung und Steuerung, p. 117. vdf Hochschulverlag AG, Zürich (2007)

15. Spiegler, V.L.M., Naim, M.M., Wikner, J.: A control engineering approach to the assessment of supply chain resilience. International Journal of Production Research 50(21), 6162-6187 (2012)

16. Meyer, M.: Logistisches Störungsmanagement inkundenverbrauchsorientierten Wertschöpfungsketten. Shaker Verlag, Aachen (2007)

17. PROLOG (ed.): Handlungsanleitung zur Störungsprävention. Ergebnisdokumentation zum Forschungsprojekt PROLOG: Prospektive Störfallkonzepte in Logistikketten der Zulieferindustrie, p. 4 (2004),

http: / /www.tu-ehemnitz.de/mb/lnstBF/prologtstart.htm 
18. Zeller, A.J.: Möglichkeiten einer maschinellen Verknüpfung von Diagnose undTherapie beim Controlling von Liefernetzen. Teil 11: Diagnose und Therapie. FORWIN-BerichtNr.: FWN-2004.005, p. 2. Bayerischer Forschungsverbund Wirtschaftsinformatik, Würzburg (2004)

19. Stiefbold, O.: Konzeption eines reaktionsschnellen Planungssystems für Logistikkettenauf Basis von Software-Agenten. Ansatz zur Planung und Steuerung von verteilten Produktionssystemen mit heterogenen IV-Systemen. Dissertation Universität Karlsruhe. Institut für Werkzeugmaschinen und Betriebstechnik (iwb), Karlsruhe (1998)

20. IPRONET (ed.): Internetbasiertes Werkzeug zur unternehmensübergreifendenkonfigurierbaren Unterstützung von produzierenden Unternehmen in Netzwerken. Abschlussbericht zum Verbundprojekt Karlsruhe (2002),

http: //www.3rs.de/ipronetliproneLAB.pdf

21. VDA (ed.): Materialien zur Automobilindustrie. Future Automotive Industry Structure (FAST) 2015. Die neue Arbeitsteilung in der Automobilindustrie. Eine Studie von Mercer Management Consulting in Zusammenarbeit mit dem Fraunhofer Institut für Produktionstechnik und Automatisierung und dem Fraunhofer Institut für Materialfluss und Logistik, Stuttgart, p. 166 (2004)

22. Lloret, J., Garcia-Sabater, J.P., Marin-Garcia, J.A.: Cooperative Supply Chain Rescheduling: The Case of an Engine Supply Chain. In: Luo, Y. (ed.) CDVE 2009. LNCS, vol. 5738, pp. 376-383. Springer, Heidelberg (2009)

23. Daohai, Z.: Study on Supply Disruption Management of Supply Chain Based on CaseBased Reasoning. In: Huang, T., Zeng, Z., Li, C., Leung, C.S. (eds.) ICONIP 2012, Part IV. LNCS, vol. 7666, pp. 668-676. Springer, Heidelberg (2012)

24. Schönsleben, P., Nienhaus, J., Schnetzler, M., Sennheiser, A., Weidemann, M.: Stand und Entwicklungstendenzen in Europa. Supply Chain Management 3(1), 19-27 (2003)

25. Heusler, K.F., Stölzle, W., Bachmann, H.: Supply Chain Event Management - Grundlagen, Funktionen und potentielle Akteure. Wirtschaftswissenschaftliches Studium 35(1), 19-24 (2006)

26. Nissen, V.: Supply Chain Event Management. Wirtschaftinformatik 44(5), 477-480 (2002)

27. Ijioui, R., Emmerich, H., Ceyp, M., Diercks, W.: Supply Chain Event Management als strategisches Unternehmensführungskonzept. In: Ijioui, R., Emmerich, M. (eds.) Supply Chain Event Management - Konzepte, Prozesse, Erfolgsfaktoren, pp. 3-13. Ceyp. Physica Verlag, Heidelberg (2007)

28. Luckham, D.: The Power of Events: An Introduction to Complex Event Processing in Distributed Enterprise Systems. Addison-Wesley Longman Publishing Co., Inc., Boston (2002)

29. Buchmann, A., Koldehofe, B.: Complex Event Processing. IT - Information Technology 51(5), 241-242 (2009)

30. Bretzke, W.-R., Stölzle, W., Karrer, M., Ploenes, P.: Vom Tracking \&Tracing zum Supply Chain Event Management - aktueller Stand und Trends. Studie der KPMG Consulting AG, Düsseldorf (2002)

31. O'Leary, D.E.: Supporting decisions in real-time enterprises: autonomic supply chain systems. Inf. Syst. E-Bus. Manage. 6, 239-255 (2008) 